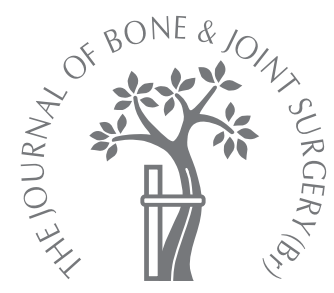

\title{
Histopathological and biochemical changes following fat embolism with administration of corn oil micelles
}

\author{
A NEW ANIMAL MODEL FOR FAT EMBOLISM SYNDROME
}

\author{
D. D. Liu, \\ N.-K. Hsieh, \\ H. I. Chen
}

From Department of Dentistry and Center for Neuropsychiatry, Taiwan

\author{
Several experimental models have been used to produce intravascular fat embolism. We \\ have developed a simple technique to induce fat embolism using corn oil emulsified with \\ distilled water to form fatty micelles. Fat embolism was produced by intravenous \\ administration of these fatty micelles in anaesthetised rats, causing alveolar oedema, \\ haemorrhage and increased lung weight. \\ Histopathological examination revealed fatty droplets and fibrin thrombi in the lung, \\ kidney and brain. The arteriolar lumen was filled with fatty deposits. Following fat \\ embolism, hypoxia and hypercapnia occurred. The plasma phospholipase $A_{2}$, nitrate/nitrite, \\ methylguidanidine and proinflammatory cytokines were significantly increased. Mass \\ spectrometry showed that the main ingredient of corn oil was oleic acid. \\ This simple technique may be applied as a new animal model for the investigation of the \\ mechanisms involved in the fat embolism syndrome.
}

The intravasation of fat after trauma may result in embolisation to the lung, brain and other organs. ${ }^{1-5}$ According to Talbot and Schemitsch, ${ }^{6}$ the first case of post-traumatic fat embolism was described by Zenker in 1862 in a patient with a crush injury. At post mortem, fat droplets were found in the pulmonary capillaries. Fat embolism syndrome due to circulatory fat emboli has been recognised subsequently as a clinical problem. ${ }^{2-}$ 4,7-9 Peltier $^{10,11}$ proposed that the neutral fat was embolised after a fracture, and caused capillary obstruction. He proposed that it was then hydrolysed by lipases in the lung to release free fatty acids which were locally toxic.

Several chemical mediators, such as phospholipase $\mathrm{A}_{2}$, platelet-activating factor, nitric oxide, and cyclo-oxygenase products, have been implicated in the pathogenesis of fat embolism syndrome. $1,7,8,12,13$ However, the ultimate mechanisms involved are yet to be determined. In order to elucidate the pathogenetic causes and to develop an effective therapeutic regimen, several experimental models have been used to simulate or to produce fat embolism. These include glucocorticoid administration to induce osteonecrosis, ${ }^{14}$ polymethylmethacrylate injection with vertebroplasty, ${ }^{15}$ intramedullary nailing, ${ }^{16,17}$ and intravenous triolein and/or oleic acid. ${ }^{12,18-20}$ Most of these procedures are rather complicated and expensive. In this study, we developed a simple technique to produce fat embolisation in anaesthetised rats.

\section{Materials and Methods}

We used 24 disease-free male Sprague-Dawley rats weighing $300 \mathrm{~g}$ to $340 \mathrm{~g}$. The animals were obtained from the National Animal Centre and housed in the University Laboratory Animal Centre with good environmental control. The study had ethical approval and followed the guidelines of the National Animal Research Centre. The room temperature was maintained at $21^{\circ} \mathrm{C}(\mathrm{SD} 1)$ with a regime of 12 hours alternating light and darkness. The rats were given unrestricted access to food and water.

The rats were anaesthetised with intravenous sodium pentobarbital $(40 \mathrm{mg} / \mathrm{kg})$ after which a femoral vein was cannulated. Pure corn oil was emulsified with distilled water, producing fatty micelles which were administered via the cannula.

One assessment of the extent of acute lung injury was inferred from changes in lung weight. This was obtained from 30 rats killed with intravenous sodium pentobarbital $(100 \mathrm{mg} / \mathrm{kg})$. The initial lung weight was estimated applying a published equation relating lung weight to the body weight. ${ }^{21}$ The lung weight was then plotted against body weight using a regression equation:

Lung weight $(\mathrm{g})=0.0015$ ? body weight $(\mathrm{g})$ $+0.034$

The gain in lungweight was calculated by subtracting the initial from the final lung weight. In order to determine the optimal 


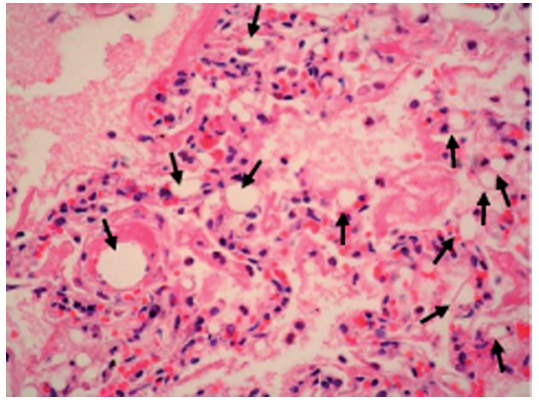

Fig. 1a

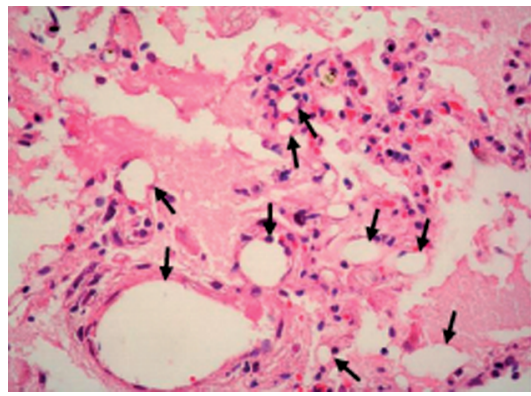

Fig. 1b

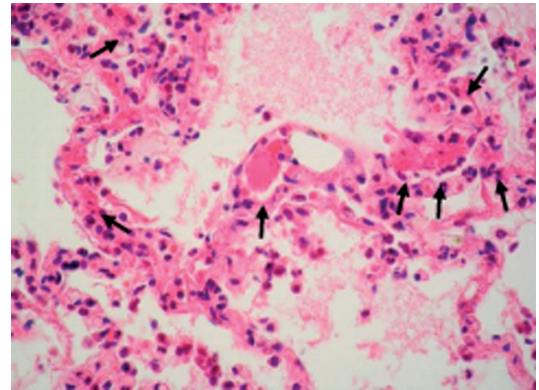

Fig. 1c

Photomicrographs of fat embolus-induced histological changes in the lung. Alveolar oedema and haemorrhage were observed. a) and b) a variety of numbers and sizes of fatty droplets were seen (arrows); c) fibrin thrombi (arrows) were demonstrated (haematoxylin and eosin stain, original magnification $\times 200$ ).

concentration of corn oil and the dose-response relationship, oil of volumes $0.1 \mathrm{ml}, 0.2 \mathrm{ml}, 0.4 \mathrm{ml}$ and $0.6 \mathrm{ml}$ was emulsified with $0.2 \mathrm{ml}$ distilled water to form fatty micelles. These were injected intravenously at a rate of $0.1 \mathrm{ml} / \mathrm{min}$ with four groups of six rats receiving each of the available concentrations. Following the injections, certain animals died within 60 minutes and the survivors were killed with an overdose of sodium pentobarbital $(100 \mathrm{mg} / \mathrm{kg})$.

All the rats underwent post mortem examination, where the lung, kidneys and brain were removed for histopathological examination. Tissue sections were immersed in $10 \%$ formaldehyde for 24 hours and then rinsed with tap water to remove the formaldehyde. For light-microscopic examination, tissue sections were dehydrated and embedded in paraffin at $60^{\circ} \mathrm{C}$. A series of $5 \mu \mathrm{m}$ sections were stained with haematoxylin and eosin. Fat staining with various methods was used to detect the presence of fatty droplets. ${ }^{22}$

Arterial blood samples $(1 \mathrm{ml})$ were taken prior to the injection of the micelles and at 50 minutes to 60 minutes afterwards to determine $\mathrm{pH}, \mathrm{PaO}_{2}$ and $\mathrm{PaCO}_{2}$ with a $\mathrm{pH}$ and blood gases analyser (ABL 5, Blood Gas Analyzer, Radiometer, American, West Lake, Ohio). Plasma concentration of phospholipase $\mathrm{A}_{2}$ was measured with a spectrofluorimeter by a method described by Kitsiouli, Nakos and Lekka. ${ }^{23}$ In brief, the standard incubation for phospholipase $\mathrm{A}_{2}$ contained $10 \mathrm{mM}$ Tris HCI buffer $(\mathrm{pH}$ 7.4) with $2 \mathrm{mM}$ calcium and $5 \mathrm{mM} \mathrm{C}_{12}$-NBD-PC as substrate. The absorbance of the reaction mixture was measured with excitation and emission wavelengths at $475 \mathrm{~nm}$ and $535 \mathrm{~nm}$, respectively.

The mean plasma concentrations of nitrate/nitrite and methylguanidine were determined with high-performance chromatography. ${ }^{21,24,25}$ Tumour necrosis factor- $\alpha$ (TNF$\alpha$ ), interleukin-1 $\beta$ (IL-1 $\beta$ ) and interleukin-6 (IL-6) were measured with antibody enzyme-linked immunosorbent assays (ELISA) using a commercial antibody pair, recombinant standards, and a biotin-streptavidin-peroxidase detection system (Endogen, Rockford, Illinois). All agents, samples and working standards were prepared at room temperature according to the manufacturer's instructions.
The optical density was measured at $450 / 450 \mathrm{~nm}$ wavelengths by automated ELISA readers. Mass spectrometry was used to determine the chemical composition of corn oil micelles.

Statistical analysis. The data were expressed as the mean and standard error of the mean (SEM). Comparisons of measured variables were made using one-way analysis of variance (ANOVA) with repeated measures, followed by a post hoc comparison with the Newman-Keul test. ${ }^{26}$ Differences were considered to be statistically significant at $\mathrm{p}<0.05$.

\section{Results}

The intravenous administration of fatty micelles caused histopathological changes in rat lung, kidney and brain. Fatty droplets and fibrin thrombin were demonstrated in the lung and alveolar oedema and haemorrhage were also observed (Fig. 1). Fat staining with oil-red, Sudan black and Sudan III revealed fatty particles in the lung parenchyma (Fig. 2) and the pulmonary arteriolar lumen was filled with fatty globules (Fig. 3). Similar changes were observed in the small arterial vessels in the kidney and brain. Histological examination also revealed fat droplets in the renal glomeruli and cerebral capillaries (Fig. 4).

The values of the lung weight/body weight ratio $(\times 100)$ and gain in lung weight following administration of corn oil $0.1,0.2,0.4$ and $0.6 \mathrm{ml}$ emulsified with $0.2 \mathrm{ml}$ distilled water are summarised in Table I. These data indicate that the mixture containing $0.2 \mathrm{ml}$ of corn oil produced a greater effect than that containing $0.1 \mathrm{ml}(\mathrm{p}<0.05$, Newman-Keul test), whereas more than $0.2 \mathrm{ml}$ of corn oil $(0.4$ and $0.6 \mathrm{ml})$ did not significantly increase the lung weight/body weight ratio and gain in lung weight $(\mathrm{p}>0.5$, Newman-Keul test). It appeared that corn oil mixture containing $0.2 \mathrm{ml}$ with the same volume of water was the optimal dose.

Chemical analysis with mass spectrometry revealed that the main ingredient of corn oil micelles was oleic acid and other unsaturated free fatty acids.

Analysis of the responses of the arterial blood $\mathrm{pH}, \mathrm{PaO}_{2}$ and $\mathrm{PaCO}_{2}$ revealed significant reductions in the mean $\mathrm{pH}$ 


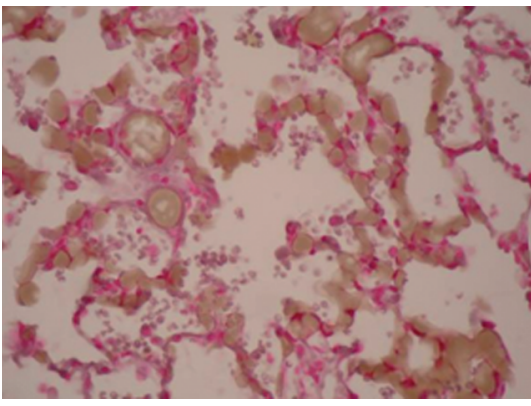

Fig. 2a

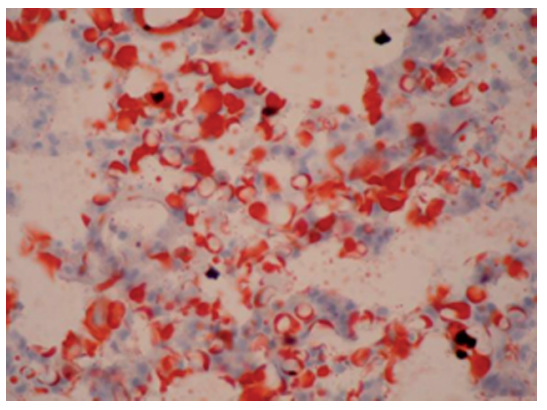

Fig. $2 b$

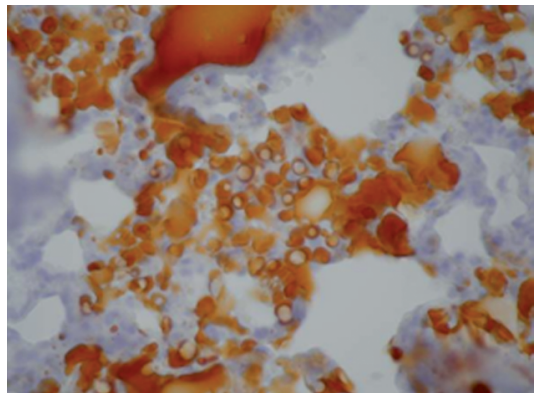

Fig. 2c

Fat stain with a) oil-red, b) Sudan black and c) Sudan III revealed fat droplets in the lung parenchyma. The droplets appear reddish, brown to black and orange in $a, b$ and $c$, respectively (original magnification? 200).

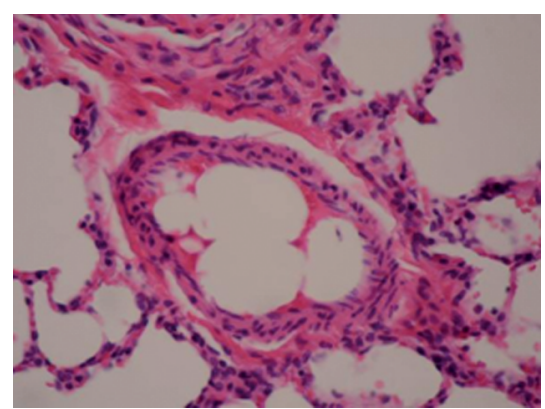

Fig. 3a

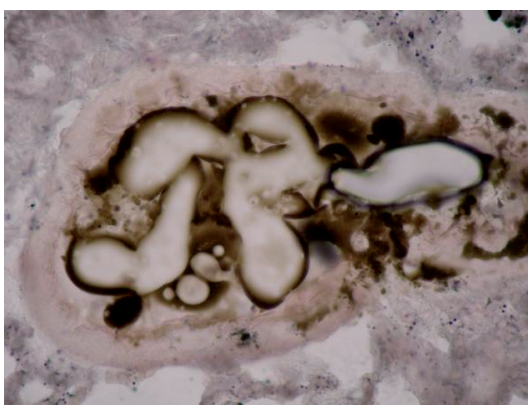

Fig. 3c

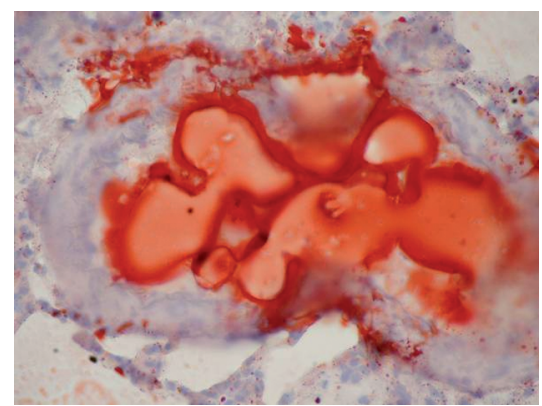

Fig. 3b

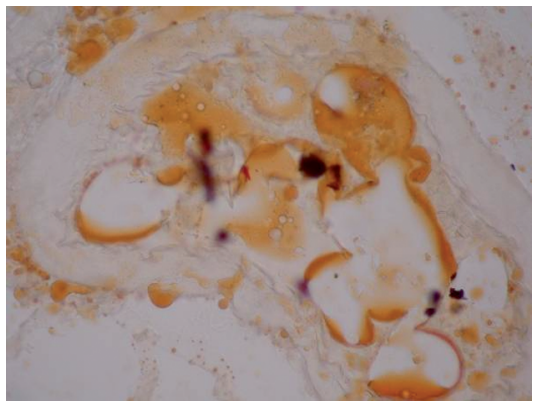

Fig. 3d

Staining of pulmonary arterioles with a) haematoxylin and eosin, b) oil-red, c) Sudan-black and d) Sudan III disclosed fatty depositions in the arteriolar lumen (original magnification ? 400).

and mean $\mathrm{PaO}_{2}$ with an increase in mean $\mathrm{PaCO}_{2}$ following administration of fatty micelles (Table II). Fat embolisation caused increases in the mean phospholipase $\mathrm{A}_{2}$ level, nitrate/nitrite and methylguanidine (Table III). In addition, the concentration of TNF- $\alpha$, IL- $1 \beta$ and IL- 6 were markedly elevated (Table IV).

\section{Discussion}

Experimental studies and clinical investigations, including those from our laboratory, have indicated that the fat embolism syndrome occurs mainly in patients with fractures of the long bones. ${ }^{1,7,8,27}$ The diagnosis is difficult and the ultimate mechanisms involved remain undetermined. ${ }^{2,8,28}$ It has been proposed that the fat embolism syndrome includes an early physical phase of microvascular pulmonary obstruction and a second late phase involving the release of free fatty acids and chemical mediators. ${ }^{10,11}$ In this study, we have demonstrated histopathological evidence of pulmonary arteriolar obliteration by fatty droplets and similar changes in other organs. The Gurd criteria, 29,30 including pulmonary, neurological and cutaneous signs and symptoms, suggest multiple organ involvement. Theoretically, intravasation of fat emboli into the circulation should result in the emboli being trapped in many organs. Experimental studies and clinical reports on cerebral fat embolism due to fat emboli or fat embolism syndrome have been documented, and associated neurological disorders have been described. ${ }^{31-33}$ Fat embolism to the kidney has rarely been reported. However, Brondén et al, ${ }^{34}$ using tritium-labelled triolein in a pig model to induce lipid microembolism and 


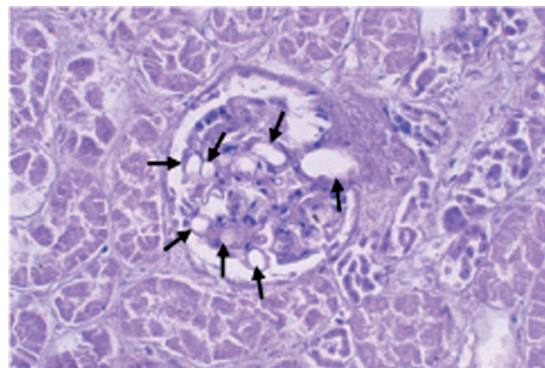

Fig. $4 \mathrm{a}$

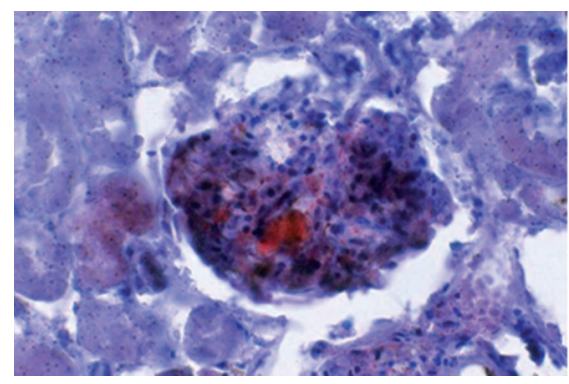

Fig. $4 b$

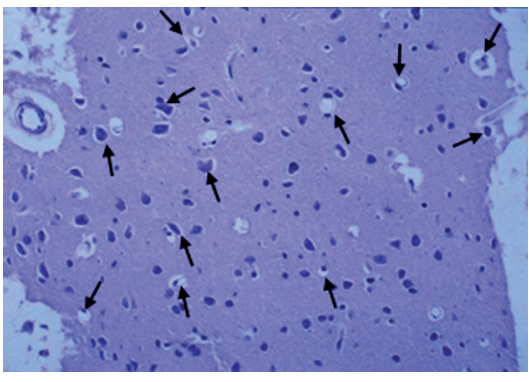

Fig. 4c

Photomicrographs of fatty droplets in the renal glomerulus, a) marked with arrows and b) brown staining, c) cerebral capillaries marked with arrows (c) (a and c, haematoxylin and eosin stain; b, fat stain (original magnification ? 400)).

Table I. Mean lung weight (LW) to mean body weight (BW) ratio and gain following the administration of corn oil of different volumes

\begin{tabular}{lll}
\hline & LW/BW (? 100) & Gain in LW (g) \\
\hline $\begin{array}{ll}\text { Volume of corn oil (ml) } \\
0.1\end{array}$ & 1.3 (SEM 0.3) & 0.5 (SEM 0.2) \\
0.2 & 2.4 (SEM 0.5) & 2.3 (SEM 0.4) \\
0.4 & 2.8 (SEM 0.8) & 2.2 (SEM 0.6) \\
0.6 & 3.2 (SEM 0.5) & 2.6 (SEM 0.8) \\
\hline
\end{tabular}

$\mathrm{n}=6$ for each corn oil volume

All statistical comparisons made with results obtained with $0.2 \mathrm{ml}$ corn oil

Table II. Mean (SEM) results for arterial blood $\mathrm{pH}, \mathrm{PaO}_{2}$ and $\mathrm{PaCO}_{2}$ following fat embolisation

\begin{tabular}{|c|c|c|c|}
\hline & pH & $\mathrm{PaO}_{2}(\mathrm{mmHg})$ & $\begin{array}{l}\mathrm{PaCO}_{2} \\
(\mathrm{mmHg})\end{array}$ \\
\hline Baseline & $7.24(0.06)$ & $95(4)$ & $37(2)$ \\
\hline After fat embolisation & $5.64(0.04)$ & $52(3)$ & $59(3)$ \\
\hline
\end{tabular}

Table III. Mean (SEM) changes in phospholipase $A_{2}$ nitrate/nitrite and methylguanidine levels following fat embolisation

\begin{tabular}{llll}
\hline & Phospholipase $\mathbf{A}_{\mathbf{2}}$ ( $\left.\mathbf{m m o l} / \mathbf{m l}\right)$ & Nitrate/Nitrite (pmol/ml) & Methylguanidine (pmol/ml) \\
\hline Baseline & $0.36 .24(0.03)$ & $19.38(1.42)$ & $1.48(0.04)$ \\
After fat embolisation & $0.79(0.08)$ & $56.84(3.61)$ & $3.42(0.26)$ \\
\hline
\end{tabular}

Table IV. The mean (SEM) concentration of tumour necrosis factor-?, interleukin-1 and interleukin- 6 before and after fat, embolisation

\begin{tabular}{llll}
\hline & Tumour necrosis factor-? $(\mathbf{p g} / \mathbf{m l})$ & IL-1? (pg/mI) & IL-6 (pg/ml) \\
\hline Baseline & $54.2(4.8)$ & $49.8(4.4)$ & $86.4(9.8)$ \\
After fat embolisation $(\mathrm{n}=12)$ & $4364.6(96.9)$ & $198.6(32.8)$ & $678.5(20.6)$ \\
\hline
\end{tabular}

found a higher density of radioactive lipid particles in the kidney and spleen than in the lung and brain. The severity and extent of involvement may depend on the sequestration of fat emboli in an organ.

In this study, we used corn oil emulsified in water to form micelles which, when administered intravenously, produced histopathological changes in the lung, kidney and brain. Our simple method produced the physical phase of fat embolism with fatty droplets in organs. Furthermore, analysis of arterial $\mathrm{pH}, \mathrm{PaO}_{2}$ and $\mathrm{PaCO}_{2}$ revealed acidosis, hypoxia and hypercapnia. Biochemical determination showed elevation of phospholipase $\mathrm{A}_{2}$, nitrate/nitrite, methylguanidine and proinflammatory cytokines, including TNF- $\alpha$, IL- $1 \beta$ and IL- 6 . Phospholipase $A_{2}$ has been shown to increase in bronchoalveolar lavage and blood in patients with fat embolism syndrome, and has been 
suggested as a diagnostic parameter. ${ }^{1,8,26}$ In two series of clinical investigations, we found that the concentration of plasma nitrate/nitrite was increased in patients with acute respiratory distress syndrome following fracture of the tibia and femur. ${ }^{7,8}$ The production of methylguanidine has been used as an indicator of hydroxyl radical formation. ${ }^{35}$ In this study we have provided evidence that the chemical phase of the fat embolism syndrome involves phospholipase $A_{2}$, nitric oxide, hydroxyl radicals and proinflammatory cytokines. Further investigations are required to compare the chemical mediators involved syndrome using our method compared to those obtained from other studies.

Mass spectrometrical analysis revealed that oleic acid was the main component in the corn oil micelles. This has commonly been used to induce acute lung injury in experimental animals. ${ }^{36-38}$ In patients with acute respiratory distress syndrome, the level of oleic acid in the blood has been shown to be significantly elevated. ${ }^{39}$ Although we had no control group, we believe the oleic acid in corn oil is probably the cause of severe acute lung injury in this animal model of fat embolism which resulted in histopathological and biochemical changes resembling clinical fat embolism syndrome. ${ }^{8}$ We acknowledge the limitations of this animal model. Our technique was not compared with the other methods and other oils containing different fatty acids. The application of corn oil micelles to isolated lung preparations may have provided more information with respect to the effects of fat embolisation on pulmonary microvascular permeability and haemodynamics.

In summary, our simple animal model of fat embolism syndrome may be used to investigate the pathogenetic mechanism of fat embolism syndrome associated with pulmonary, cerebral and renal dysfunction.

This study was supported in part by grants from the National Science Counci (NSC95-2320-B320-008).

No benefits in any form have been received or will be received from a com mercial party related directly or indirectly to the subject of this article.

\section{References}

1. Karagiorga G, Nakos G, Galiatsou E, Lekka ME. Biochemical parameters of brochoalveolar lavage fluid in fat embolism. Intensive Care Med 2006;32:116-23.

2. Mellor A, Soni N. Fat embolism. Anaesthesia 2001;56:145-54.

3. Habashi NM, Andrews PL, Scalea TM. Therapeutic aspects of fat embolism syndrome. Injury 2006;37(4 suppl):68-73.

4. Giannoudis PV, Tzioupis C, Pape HC. Fat embolism: the reaming controversy. Injury 2006;37(4 suppl):50-8

5. Riding G, Daly K, Hutchinson S. Paradoxical cerebral embolisation: an explanation for fat embolism syndrome. J Bone Joint Surg [Br] 2004;86-B:95-8.

6. Talbot M, Schemitsch EH. Fat embolism syndrome: history, definition, epidemiology. Injury 2006;37(4 suppl):3-7.

7. Hsu YH, Kao SJ, Lee RP, Chen HI. Acute pulmonary oedema: rare causes and pos sible mechanisms. Clin Sci (Lond) 2003;104:259-64

8. Kao SJ, Yeh DY, Chen HI. Clinical and pathological features of fat embolism with acute respiratory distress syndrome. Clin Sci (Lond) 2007;113:279-85.

9. Kontakis GM, Tossounidis T, Weiss K, Pape HC, Giannoudis PV. Fat embolism: special situations: bilateral femoral fractures and pathologic femoral fractures. Injury 2006:37:19-24.

10. Peltier LF. Fat embolism: a current concept. Clin Orthop 1969;66:241-53.
11. Peltier LF. Fat embolism: a perspective. Clin Orthop 1988;232:263-70.

12. Nakata Y, Tanaka H, Kuwagata Y, Yoshioka T, Sugimoto H. Triolein-induced pulmonary embolization and increased microvascular permeability in isolated perfused rat lungs. J Trauma 1999;47:111-19.

13. Rae D, Porter J, Beechey-Newman N, et al. Type 1 prophospholipase A2 propeptide in acute lung injury. Lancet 1994;344:1472-3.

14. Fukui K, Kominami R, Shinohara H, Matsumoto T. Glucocorticoid induces microfat embolism in the rabbit: a scanning electron microscopic study. J Orthop Res 2006;24:675-83

15. Aebli N, Schwenke D, Davis G. Polymethylmethacrylate causes prolonged pulmonary hypertension during fat embolism: a study in sheep. Acta Orthop 2005;76:904-11.

16. Buttaro M, Mocetti E, Alfie V, Paniego G, Piñeiro L. Fat embolism and related effects during reamed and unreamed intramedullary nailing in a pig model. $J$ Orthop Trauma 2002:16:239-44.

17. Schemitsch EH, Jain R, Turchin DC, et al. Pulmonary effects of fixation of a fracture with a plate compared with intramedullary nailing: a canine model of fat embolism and fracture fixation. J Bone Joint Surg [Am] 1997;79-A:984-96.

18. Kim HJ, Lee CH, Kim HG, et al. Reversible MR changes in the cat brain after cerebral fat embolism induced by triolein emulsion. AJNR Am J Neuroradio/ 2004;25:958-63.

19. Kim HJ, Lee JH, Lee CH, et al. Experimental cerebral fat embolism: embolic effects of triolein and oleic acid depicted by MR imaging and electron microscopy. AJNR Am $J$ Neuroradio/ 2002;23:1516-23.

20. Young JS, Rayhrer CS, Edmisten TD, et al. Sodium nitroprusside mitigates oleic acid-induced acute lung injury. Ann Thorac Surg 2000;69:224-7.

21. Chen HI, Yeh DY, Liou HL, Kao SJ. Insulin attenuates endotoxin-induced acute lung injury in conscious rats. Crit Care Med 2006;34:758-64

22. Tracy RE, Walia P. A method to fix lipids for staining fat embolism in paraffin sections. Histopathology 2002;41:75-9.

23. Kitsiouli El, Nakos G, Lekka ME. Differential determination of phospholipase A(2) and PAF-acetylhydrolase in biological fluids using fluorescent substrates. J Lipid Res 1999;40:2346-56.

24. Hsu BG, Lee RP, Yang FL, Harn HJ, Chen HI. Post-treatment with N-acetylcysteine ameliorates endotxin shock-induced organ damage in conscious rats. Life Sci 2006;79:2010-16.

25. Muscará MN, de Nucci G. Simultaneous determination of nitrite and nitrate anions in plasma, urine and cell culture supernatants by high-performance liquid chromatography with post-column reactions. J Chromatogr B Biomet App/1996;686:157-64.

26. Otano A, García-Osta A, Ballaz S, Frechilla D, DelRió J. Facilitation by 8-0-HDPAT of passive avoidance performance in rats after inactivation of 5-HT (1A) receptors. Br J Pharmacol 1999;128:1691-8.

27. Roger N, Xaubert A, Agusti C, et al. Role of bronchoalveolar lavage in the diagnosis of fat embolism syndrome. Eur Respair J 1995;8:1275-80.

28. White T, Petrisor BA, Bhandari M. Prevention of fat embolism syndrome. Injury 2006;37:59-67.

29. Gurd AR. Fat embolism: an aid to diagnosis. J Bone Joint Surg [Br] 1970;52-B:732-7.

30. Gurd AR, Wilson RI. The fat embolism syndrome. J Bone Joint Surg [Br] 1974;56B:408-16

31. Kamenar E, Burger PC. Cerebral fat embolism: a neuropathophysiological study of a microembolic state. Stroke 1980;11:477-84.

32. Kim HJ, Lee CH, Lee SH, Moon TY. Magnetic resonance imaging and histologic findings of experimental cerebral fat embolism. Invest Radiol 2003;38:625-34.

33. Parizel PM, Demey HE, Veeckmans G, et al. Early diagnosis of cerebral fat embolism syndrome by diffusion-weighted MRI (starfield pattern). Stroke 2001;32:2942-4.

34. Brondén B, Dencker M, Allers M, Plaza I, Jönsson H. Differential distribution of lipid microemboli after cardiac surgery. Ann Thorac Surg 2006;81:643-8.

35. Nakamura K, lenaga K, Yokozawa T, Fujitsuka N, Oura H. Production of methylguanidine from creatinine via creatol by active oxygen species: analyses of the catabolism in vitro. Nephron 1991;58:42-6.

36. Vadász I, Morty RE, Kohstall MG, et al. Oleic acid inhibits alveolar fluid reabsorption: a role in acute respiratory distress syndrome? Am J Respir Crit Care Med 2005;171:469-79.

37. Lim SC, Adams AB, Simonson DA, et al. Transient hemodynamic effects of recruitment maneuvers in three experimental models of acute lung injury. Crit Care Med 2004;32:2378-84.

38. Lim SC, Adams AB, Simonson DA, et al. Intercomparison of recruitment maneuver efficacy in three models of acute lung injury. Crit Care Med 2004;32:2371-7.

39. Bursten SL, Federighi DA, Parsons $\mathbf{P}$, et al. An increase in serum C18 unsaturated free fatty acids as a predictor of the development of acute respiratory distress syndrome. Crit Care Med 1996;24:1129-36. 